$5-28-2021$

\title{
The Healing of Historical Collective Trauma
}

Eugen Koh

Melbourne School of Population and Global Health, University of Melbourne

Follow this and additional works at: https://digitalcommons.usf.edu/gsp

\section{Recommended Citation}

Koh, Eugen (2021) "The Healing of Historical Collective Trauma," Genocide Studies and Prevention: An International Journal: Vol. 15: Iss. 1: 115-133.

DOI:

https:// doi.org/10.5038/1911-9933.15.1.1776

Available at: https://digitalcommons.usf.edu/gsp/vol15/iss1/10

This Articles is brought to you for free and open access by the Open Access Journals at Digital Commons @ University of South Florida. It has been accepted for inclusion in Genocide Studies and Prevention: An International Journal by an authorized editor of Digital Commons @ University of South Florida. For more information, please contact digitalcommons@usf.edu. 


\section{The Healing of Historical Collective Trauma}

\section{Acknowledgements}

I wish to acknowledge the guidance of Dr. George Halasz and Dr. Paul Valent for my consideration of the Holocaust; the views expressed, and any errors, are entirely mine alone. 


\title{
The Healing of Historical Collective Trauma
}

\author{
Eugen Koh \\ Melbourne School of Population and \\ Global Health, University of Melbourne \\ Melbourne, Australia
}

\section{Introduction 1}

World Wars are, without question, defined traumatic events that change the course of history and leave a legacy that persists not only in the lives of individuals and their descendants but also on the geopolitical instability we see around the world today. ${ }^{2}$ Genocides are in some ways more complex than wars. They are rarely isolated events; taking place within centuries-old fomenting hatred and rivalry, they involve not only systematic killing but also the distortion and destruction of cultures. ${ }^{3}$ Beyond the killings are the more insidious traumatic collective experiences which are difficult to describe, let alone define.

We can understand these experiences more clearly when we consider the systematic and institutionalized destruction of First Nations people through geographical and cultural dispossession, and continuing disempowerment and discrimination. The process of cultural dispossession that occurs with colonization over generations can be subtle, but its long-term impact may be nothing less than genocidal; indeed, it can be viewed as genocide in slowmotion. 4

In many circumstances, these slow and gradual forms of collective trauma are both historical and continuing. It does not make sense to talk about healing in such situations but rather of repairing wounds from an historical event. There must also be accompanying efforts to expose and bring to an end a process of continuing assault and injury. Efforts to formulate a theory on the healing of historical collective trauma is complex; it is complicated further by a lack of agreement over the definition of trauma, and uncertainty as to how knowledge about individual psychology can be applied to collectives.

This paper is in three parts. It begins by clarifying key concepts such as trauma, collective experience and shared consciousness. Next, it proposes a framework for considering the healing of historical collective trauma and discuss a range of relevant ideas and concepts, in particular the psychology of trauma. Finally, it discusses cultural trauma, a particular type of collective trauma.

Historical collective trauma is a multidimensional, multifaceted problem that cannot be addressed by a single perspective or discipline; many disciplines have indeed contributed to making sense of it. What is needed is the integration of some of these insights from different perspectives. This paper is an attempt to do that from the vantage point of a practitioner with a psychoanalytic background who has, over the past twenty years, worked with individuals and groups (including communities and societies) who have tried to make sense of their own

\footnotetext{
1 This present paper builds on papers presented to two UNESCO/Guerrand-Hermes Foundation for Peace symposiums; an unpublished paper, "Trauma and Slavery" (Koh, 2018) contributed for discussion at the symposium Healing the Wounds of Slavery: Towards Mutual Recovery, Berkley Center for Religion, Peace \& World Affairs at Georgetown University, Washington, D.C. on October 18-19, 2018 and "Collective Healing of Trauma," a symposium in London in September 2019.

2 This observation is explored in Salman Akhtar, Mind, Culture, and Global Unrest: Psychoanalytic Reflections (London: Routledge, 2018).

${ }^{3}$ Adam Jones, Genocide: A Comprehensive Introduction (Oxford: Routledge, 2016).

${ }^{4}$ A. Dirk Moses, ed., Genocide and Settler Society: Frontier Violence and Stolen Indigenous Children in Australian History (New York: Berghahn Books, 2004).

Eugen Koh. "The Healing of Historical Collective Trauma." Genocide Studies and Prevention 15, no. 1, 115-133. https:// doi.org/10.5038/1911-9933.15.1.1776.

(C) 2021 Genocide Studies and Prevention.
} 
experience of a particular historical collective trauma. They included the Aboriginals ${ }^{5}$ from the deserts of central Australia, ${ }^{6}$ survivors (and transgenerational survivors) of the Holocaust, ${ }^{7}$ Cambodian genocides, Northern Ireland, and a multidisciplinary group senior academics and practitioners in Japan who are trying to address the transgenerational legacy of their role in the Second World War. ${ }^{8}$

\section{Clarification of Key Concepts}

In this section, I will explore ways to understand some of the key concepts involved in collective trauma and healing. Conceptual clarifications such as these are essential in analyzing the root causes and effects of trauma and can also create space for exploring healing in a holistic way.

\section{The Collective}

According to The Shorter Oxford Dictionary, the word "collective" is an adjective "denoting or representing a number of individuals or items." 9 There are many different approaches to understanding a collective, each reflecting particular presuppositions, underpinning concepts and frameworks. For instance, sociological perspectives focus on describable social networks, structures and processes ${ }^{10}$ while psychological approaches consider behaviors and possible underlying dynamics, some of which are observable in the conscious realm, and some operating in the unconscious. ${ }^{11}$ Despite these differences, there is general agreement that a collective has some form of shared consciousness, whether it is conceptualized as "social history," shared memory or, a group or collective mind.

Social science tends to focus on describing what can be seen and considered as being a collective from the perspective of the individual; it views a collective as made up of individuals and construes what is observed as no more than the sum of the individuals. The idea of the group as a single "whole" entity does not sit easily within this perspective. The view adopted in this paper assumes the existence of a group or collective mind whose characteristics are distinct from and more than the sum of its constituting individual minds.

The year 2020 marks one hundred years since the publication of The Group Mind by William McDougall.12 Its conceptualization of a collective consciousness was anticipated by studies into the psychology of the crowd, most notably in the work of Le Bon. ${ }^{13}$ The idea that a collective has a singular consciousness was employed by Freud ${ }^{14}$ and more recently, by large

\footnotetext{
${ }^{5}$ I have mainly used the term Aboriginals in this paper because those that I have worked with have referred to themselves as such; in other contexts, they might have preferred to be considered collectively as Indigenous, or First Nations people, or most commonly, by the name of their regional group.

${ }^{6}$ Eugen Koh, "Cultural Work in Addressing Violence and Conflict in Traumatized Communities," New England Journal of Public Policy 31, no. 1 (2019), 1-14, accessed April 24, 2021, https://scholarworks.umb.edu/nejpp/vol31/iss1/3/.

7 Eugen Koh and George Halasz, "Back of House/Under the House: Some Psychoanalytic Aspects of the Acquisition and Exhibition of Art by Survivors of the Holocaust," International Journal of Applied Psychoanalytic Studies 8, no. 1 (2011), 74-88, accessed April 21, 2021, https://doi.org/10.1002/aps.276.

8 Eugen Koh and Tadashi Takeshima, “The Long-Term Effects of Japan's Traumatic Experience in the Second World War and its Implications for Peace in Northeast Asia," New England Journal of Public Policy 32, no. 2 (2020), 1-13, accessed December 21, 2020, https://scholarworks.umb.edu/nejpp/vol32/iss2/5/.

9 Shorter Oxford Dictionary, 6th ed. (Oxford: Oxford University Press, 2007), s.v. "collective," 451.

10 Christina Prell, Social Network Analysis: History, Theory \& Methodology (London: Sage Publications, 2012); Jeffrey C. Alexander, Ronald N. Jacobs, and Philip Smith, eds., The Oxford Handbook of Cultural Sociology (New York: Oxford University Press, 2012).

${ }^{11}$ Salman Akhtar and Stuart W. Twemlow, eds., Textbook of Applied Psychoanalysis (Abingdon: Routledge, 2018).

12 William McDougall, The Group Mind (London: Cambridge University Press, 1920).

${ }^{13}$ Gustave Le Bon, Psychologie des foules (Paris: Félix Alcan, 1895).

14 Sigmund Freud, "Group Psychology and the Analysis of the Ego," in Vol. 18, The Standard Edition of The Complete Psychological Works of Sigmund Freud, ed. James Strachey (London: Hogarth Press, [1921] 1955), 67-143.
} 
numbers of writers on different areas of collective life, including politics, ${ }^{15}$ the arts, ${ }^{16}$ and culture. ${ }^{17}$ Unlike within social science, there appears to be an implicit assumption, without debate or elaboration, in the vast psychoanalytic literature that the collective life consists of a singular consciousness. It might be argued that because so many writers have adopted this notion of a singular consciousness in collective life, and that their writing makes sense to a growing readership, this offers some validation of this view.

I wish to highlight, however, that there is usually a complex interplay between the individual and the collective mind; it would be an oversimplification to insist that only one of these is in operation. For the purposes of this paper, I focus mainly on the collective mind.

\section{Trauma}

It might surprise the reader that there is no universal agreement on the definition of trauma despite its widespread usage. The current popular understanding of trauma as injury and damage, has its roots in the Greek word, trauma, which means wound. Emmanouil Pikoulis et al. noted that in ancient Greek medicine, the term was used to refer to a wound, and the earliest recorded use of trauma in the English language was in Steven Blankart's "Physical Dictionary," published in 1684, where it referred to "... a Wound from an external Cause."18 Hence the specialty of traumatology and establishment of specialized trauma centers for life-threatening bodily injuries from motor vehicle accidents, shootings, natural disasters, etcetera. MacCabe and Yanacek noted:

Once a relatively straightforward term, trauma, with its broadened psychological sense, has been contested and intensely politicized over the past decades. Like, Victim, the word has been used by individuals and groups to make the extent of their suffering known and to advocate particular political agendas. Trauma has become so generalized that almost any negative experience may now qualify as trauma. ${ }^{19}$

Notwithstanding this trend, the field of psychiatry, as a specialty of medicine, has attempted to maintain a more narrowly defined understanding of psychological trauma as that which emerged from the concept of shell-shock during the First World War and is now understood as post-traumatic stress disorder (PTSD).

There is, however, another line of development in the conceptualization of trauma, in reaction to the narrow medical definition of PTSD. As Sonya Andermahr noted:

The field of trauma studies emerged in the early 1990s as an attempt to construct an ethical response to forms of human suffering and their cultural and artistic representation. Born out of a confluence between deconstructive and psychoanalytic criticism and the study of Holocaust literature, from its outset trauma theory's mission was to bear witness to traumatic

\footnotetext{
${ }_{15}$ Andrew Samuels, The Political Psyche (London: Routledge, 1993); Paul Hoggett, Politics, Identity and Emotions (Boulder: Paradigm Publishers, 2009); Vamik D. Volkan, Psychoanalysis, International Relations and Diplomacy: A Sourcebook on Large-Group Psychology (London: Karnac, 2014).

16 Ellen Handler Spitz, Art and Psyche (New Haven: Yale University Press, 1985); James W. Hamilton, A Psychoanalytic Approach to Visual Artists (London: Karnac, 2012).

17 James Donald, ed., Psychoanalysis and Cultural Theory (London: MacMillan Education, 1991); Akhtar, Mind, Culture and Global Unrest.

18 Emmanouil A. Pikoulis et al., "Trauma Management in Ancient Greece: Value of Surgical Principles through the Years," World Journal of Surgery 28, no. 4 (2004), 425-430.

${ }^{19}$ Colin MacCabe, Holly Yanacek, and The Keywords Project, eds., Keywords for Today: A 21st Century Vocabulary (New York: Oxford University Press, 2018), 358.
} 
histories in such a way as to attend to the suffering of the other. ${ }^{20}$

Participants at this meeting expressed concern with the universalism and homogenization of PTSD which considers trauma from a Euro-American western framework, noting that "decolonizing trauma studies is not just about expanding the scope, broadening the focus, but also about critically examining and revising dominant conceptions of trauma and recovery." 21 Accordingly, this field has not offered a definition of trauma but highlights the importance of context within respective assumed paradigms.

I have highlighted the politics of defining trauma because of the contested nature of this field, and attempts to pretend otherwise, assuming a dominant view at the expense of others, is, of course, the very nature of colonization and, as I propose later in this article, the essence of cultural trauma. I return to this issue of a definition of trauma once I have explained the importance of culture and the significance of cultural trauma. I propose a broader notion of trauma in that light. I depart from individual psychology and PTSD by first introducing the concept of collective trauma, and the possibility of shared traumatic experience.

\section{Collective Trauma}

If we assume an experience beyond that of a single individual, i.e. by two or more people, to be collective in nature, then their shared traumatic experience may be described as a collective trauma. However, on closer examination, for an experience to be considered collective implies that there is a degree of sameness in the subjectivity of that experience. I refer to "a degree of sameness" because it is not possible, by definition, for two individuals to possess identical subjectivity. Similarly, we can speak of shared experience but not shared subjectivity. In the case of collective trauma, we can consider some degree of sameness in their wound.

Can we assume the 6 million Jews who perished during the Holocaust, and the many millions more who survived it, had similar subjective experiences? While the total experience of each of those people cannot be identical, they would have included a certain degree of shared experience based on their commonality of geography or, more generally, in their identification as Jewish. The traumatic experience of a collective encompasses components of both collective or shared trauma and personal, individual trauma.

One might distinguish a shared experience of trauma grounded in geographical commonality as collective trauma (e.g. where everyone from a single village is interned, tortured, and killed together), while the shared experience of trauma based on one's identity, ethnicity, or culture is, I propose, one of cultural trauma.

I now turn to the main focus of this paper, which is collective trauma, or more specifically, historical collective trauma. Cultural trauma is a subset and unique form of collective trauma which I return to in the last part of this article.

\section{Historical Collective Trauma}

A (Brief) Psychology of Historical Collective Trauma

Much of what follows has its roots in the individual psychology of trauma. Historically, proposals for a collective psychology had their origins in individual psychology. For instance, Freud's analysis of the church and the army in terms of group psychology rested heavily on his formulation of individual psychology with regard to unconscious motivations such as libidinal ties, symptom formation, and defenses. ${ }^{22}$ The notion of a social defense against anxiety proposed by Elliott Jaques and Isabel Menzies had its origin in theories of ego defense

\footnotetext{
20 Sonya Andermahr, "Introduction," in "Decolonizing Trauma Studies: Trauma and Postcolonialism," ed. Sonya Andermahr, special issue, Humanities 4, no. 4 (2015), 500.

${ }^{21}$ Stef Craps et al., "Decolonizing Trauma Studies Round-Table Discussion," in "Decolonizing Trauma Studies: Trauma and Postcolonialism," ed. Sonya Andermahr, special issue, Humanities 4, no. 4 (2015), 907.

22 Freud, Group Psychology, 96-97.
} 
mechanisms and object relations, developed from considerations of the mind of the individual. ${ }^{23}$ It is common nowadays for writers to explore collective psychology using the language and concepts of individual psychology as if they were interchangeable. ${ }^{24}$

There is no doubt, however, among those who work with large groups and populations, that collective psychology is quite different from individual psychology. There are not yet sufficient conceptual frameworks in the field of collective psychology for it to stand alone; hence the need to borrow from and extend the use of our understanding of the individual to the collective mind. While it might be argued that individual psychology cannot be applied directly to a consideration of groups and populations, it does not follow that its language and concepts may not be utilized for tentative preliminary formulations, out of which a more elaborate collective psychology may be established. It is, in my view, possible to use the framework of individual psychology as long as we are mindful of these caveats.

Some might wonder: why are we discussing the psychology of trauma when an event is historical? It will be apparent in the ensuing sections that when one is triggered into a traumatic mental space there is a sense of timelessness; what was an historical event is now very present and the individual and the collective mind operates in a particular way. I will discuss these psychological processes in the subsequent pages thematically.

\section{Trauma is Timeless}

It would be inaccurate to describe the trauma suffered by the Aboriginals in Australia as "historical" even though it began over 200 years ago. Colonization is one of the more devastating forms of cultural trauma; it is a continuous, insidious process of undermining and destroying the culture of the colonized. This contrasts with the form of cultural trauma outlined by Jeffrey Alexander, where defined events, such as specific incidences of massacres, can be identified within the context of history. While these events are deemed historical with regard to the linear dimension of time, they are indeed timeless psychologically.

The traumatic wound is not bound by time. When an individual mind finds itself in a mental space where it re-encounters a traumatic event from years ago, it does not re-experience it as an historical event of the past but as something that is occurring very much in the present and it responds to that experience accordingly. 25

We can observe the so-called timelessness of collective traumatic experiences when a population responds to a present-day crisis as if it takes them back to a critical event in the past. I am using the phrase "takes them back" rather than reminding because it is not a matter of memory but one of re-experiencing the present as if the past was occurring in totality.

\section{Emotional Disassociation}

One of the first things that happen during an overwhelming traumatic experience is the disassociation of the emotional response associated with it. The individual mind feels numb. Collectively, it is experienced as a gathering of people devoid of emotionality-there is either an

\footnotetext{
${ }^{23}$ Elliott Jaques, "Social Systems as a Defence against Persecutory and Depressive Anxiety," in New Directions in Psychoanalysis, ed. Melanie Klein et al. (London: Tavistock Publications, 1955); Isabel E. P. Menzies, "A Case Study in the Functioning of Social Systems as a Defence against Anxiety: A Report on a Study of the Nursing Service of a General Hospital," Human Relations 13, no. 2 (1960).

${ }^{24}$ Lionel F. Stapley, The Personality of the Organization: A Psycho-Dynamic Explanation of Culture and Change (London: Free Association Books, 1996); Halina Brunning and Mario Perini, eds., Psychoanalytic Perspectives on the Turbulent World (London: Karnac, 2010); Lene Auestad, ed., Nationalism and the Body Politic: Psychoanalysis and the Rise of Ethnocentrism and Xenophobia (London: Karnac, 2014).

${ }^{25}$ For instance, one of my patients, a man in his forties, has traumatic memories of violence between family members during his childhood. When he was away from his family, he was able to have some insight into the violence in his family as events of the past. However, on occasions when his family gathered, such as Christmas, it felt to him that the situation was recurring; a replay, not with him as an adult but as a child. The situation was experienced by him as in the present rather than the past.
} 
eerie silence or a sense of frozenness; or the situation may be filled with frantic activity, perhaps even noisy, but devoid of meaningful emotional interactions and exchanges.

Some of the main emotions the traumatized mind (both individual and collective) seeks to isolate and avoid are shame and humiliation; these emotions seem to be an integral part of a traumatic experience. It is understandable that we are prone to feeling ashamed and humiliated when we are traumatized, because such overwhelming experiences expose our deepest vulnerability. ${ }^{26}$

\section{Encapsulation of Trauma}

Next, the mind tries to protect itself by separating the traumatic wound from the rest of it so that it can continue to function. Technically, the mind is said to repress or dissociate the trauma; commonly, we speak of forgetting. This process is usually spoken of as encapsulation, a wrapping up of the wound and hiding it from consciousness. ${ }^{27}$

One of the more consistent observations of massive trauma such as genocides is the collective unwillingness or inability to talk about it in its aftermath; there is often a collusive silence in the generation that had direct experience of that trauma. ${ }^{28}$ This has been seen in the large population of Holocaust survivors who migrated to Melbourne in the aftermath of the Second World War, and also in survivors of the Armenian and Cambodian genocides. ${ }^{29}$ Such denial is not exclusive to survivors of genocides; the same occurs in the context of major disasters and war, for example, the Japanese response to the 2011 Great East Japan Earthquake and Tsunami, and Second World War. ${ }^{30}$ Denial and the avoidance of triggers (which takes us back to the traumatic situation) are understandable behaviors when one considers how painful it is to talk about catastrophic losses and emotionally overwhelming experiences.

\section{Triggering}

The mind is said to be triggered when it becomes re-exposed to a trauma and the previously successful encapsulation breaks down. ${ }^{31}$ The emotional silence that would otherwise be present, now broken, is overcome with emotional outpourings; that eerie silence, in retrospect, would have been like the calm before the storm, or the receding sea before the tsunami.

Individuals who have been triggered are emotionally overwhelmed and often report symptoms consistent with PTSD, namely flashbacks, withdrawal, and numbing of emotionality. Collectively, there may be an initial intense emotionality in the group associated with periodic outbursts of violence. The mind tries to re-package or re-encapsulate the trauma-if it is successful, there is a return to emotional detachment; if unsuccessful, regression will follow.

Regression

The mind "falls back" (just as an overwhelmed army retreats) to preserve itself; we refer to this as regression. Psychologically, regression refers to the process whereby the mind operates at an earlier form of itself; a form deemed to be psychically more economical. ${ }^{32}$ I have previously

\footnotetext{
26 Based on author's professional expert observations.

27 Earl Hopper, "Encapsulation as a Defence against the Fear of Annihilation," The International Journal of Psycho-Analysis 72, no. 4 (1991), 607-624.

28 Yael Danieli, ed., International Handbook of Multigenerational Legacies of Trauma (New York: Plenum Press, 1998); Natan P. F. Kellermann, Holocaust Trauma: Psychological Effects and Treatment (New York: iUniverse Inc., 2009).

${ }^{29}$ This observation has emerged from my discussions with individuals who have survived these genocides. Also see note 6 .

30 Several of my Japanese colleagues have compared the denial of the Fukushima nuclear plant disaster in the wake of the 2011 Earthquake and tsunami with their denial of the Second World War. See also note 4.

31 Bessel van der Kolk, The Body Keeps the Score: Brain, Mind, and Body in the Healing of Trauma (New York: Viking, 2014). This is also based on author's professional expert observations.

32 Jean Laplanche and Jean-Bertrand Pontalis, The Language of Psycho-Analysis (London: Karnac Books, 1973).
} 
reported on my observations of collective regression in the traumatized Aboriginal communities in the Central Desert of Australia which noted at least four levels of regression. ${ }^{33}$

Firstly, the mind regresses to a more basic form of thinking; retreating from a complex thinking mode to binary thinking. When a mind can only think in binary terms, there are only two possibilities; black/white, good/bad, present/absent-it is unable to consider the possibilities of grey or a third option. President George Bush Jr. famously declared in the aftermath of the Twin Towers terrorist attacks of September 11 (in the binary thinking mode): "Either you are with us, or you are with the terrorist." 34 In this situation, there was only "us" or there were enemies. There was no possibility of neutrality. Collectively, binary thinking expresses itself as an extreme polarization or split in a population.

I propose there is another mode of thinking that is even more basic than binary, i.e. unitary thinking. In this form of thinking, which is hardly thinking at all, there is only I/ us, and no Other. I wonder if this form of thinking occurs during genocides, where the Other is not even allowed to exist as an enemy, but must be obliterated, and only I/ us can conceivably exist.

Secondly, if the first level of regression fails, the mind regresses further to the next level, with a heightened concern about threat to its "sense of identity and boundary." Individuals try to shore up their physical boundaries by isolating themselves into confined spaces (e.g. afraid to leave their home) or build taller fences or become preoccupied about how they are different from others (symbolic boundaries), which might present as a concern about identity. Often, their "preoccupation of difference" from Others deteriorates into a "fear of Others," manifesting as a greater concern about the enemy, or presenting, for instance, deceptively as benign racism.

Thirdly, the regression becomes characterized by fragmentation. In the individual, the mind is no longer able to think (it can only react) and there is a lack of a cohesive sense of self. This is characterized by a paralyzing ambivalence and conflict within, and an experience of the unbearable anxiety of falling apart. Fragmentation is more easily apparent in the collective. In the most severely traumatized Aboriginal communities, there is no longer a "community" in the sense of having a subjective sense of being a collective among themselves, nor is there common identification as one. In that situation, there is no collective voice and a collective decision is almost impossible to reach. Structurally and functionally, the so-called community is fragmented into kinship groups, and sometimes even that level of organization barely holds; the fragmentation deteriorates from extended kinship "families" into core families.

Fourthly, in this final level of regression, the mind is no longer concerned about the Other; threat is therefore no longer about identity (or boundaries), and they are no longer concerned about external enemies. The threat is experienced as coming from within and the focus is wholly existential: will they continue to exist? The leaders and elders from some of the severely traumatized Aboriginal communities I worked with expressed great concern about their continuing existence, especially in terms of the loss of their culture and the future of their offspring. In some of these communities, there was a sense of implosion and disintegration.

With an understanding of the psychology of historical collective trauma, as outlined above, I next proceed with a proposal for a working model for its healing.

\section{A Framework for Healing Collective Trauma}

Some might judge the collective trauma of the Aboriginals in Australia to be a descent down the spiral of regression to a place of irretrievable despair. I have observed, however, that in some instances they have courageously confronted their unbearably painful situation and climbed out of the darkest places. Although they have undertaken this work to heal from their cultural trauma collectively, many have also found the need to heal as individuals from their personal losses and grief, and the trauma from violence.

\footnotetext{
33 Ibid., 4.

${ }^{34}$ George W. Bush, "State of the Union Address: Text of George Bush's Speech," The Guardian, September 21, 2001, accessed April 27, 2020, https://www.theguardian.com/world/2001/sep/21/september11.usa13.
} 
There are many dimensions to the trauma experienced by a group of people: 1) there is the personal trauma of the individuals that make up the collective, 2) there are the shared traumatic experiences amongst groups of individuals within the collective, and 3) there is the traumatic wound of the collective as a singular whole entity. ${ }^{35}$ Usually, each of these aspects may involve a particular focus, and require a different approach to healing. Sometimes, however, an opportunity arises where a gathering of people might encounter healing at all three levels: as a personal experience, as a shared experience with others, and as a collective whole.

When we speak of collective healing, we usually have in mind, "healing together," consisting of some aspects of the personal and the shared. We might not be thinking of the healing of the collective as a single entity. However, when we focus on healing as a collective, it is likely there will also be healing, to varying degrees, from personal and shared trauma. I will focus from this point on the healing of shared trauma and that of the collective whole, beginning with some of the key aspects of what such a healing would entail.

\section{Safe and Supportive Environment}

In my experience as a psychotherapist, one of the first and most basic requirements for the healing of traumatic wounds is a safe and supportive space. In order for a traumatic wound to heal, it needs to be exposed. However, when we approach such exposure, we may anticipate as overwhelming, the possible humiliation from revealing our most vulnerable self, and that it is "too much" to overcome alone. The greater part of therapy is primarily the creation of an "emotionally" safe and supportive environment where such pain can be overcome with the help of a trusted Other.

It is a much more difficult task to create such an environment for hundreds or thousands of people, and perhaps almost impossible, for a whole nation consisting of millions, with varied social identifiers across a broad geography. Safety in these contexts involves more than an absence from physical threats; it includes political and cultural safety. A politically safe environment allows differences of identity, opinion and values. It is also underpinned by the principles of respect, fairness and justice. Some would add that such a space should be free from prejudice and discrimination. It might be possible to create such a space framed by these principles in a self-selected gathering of a few hundred; it is much more difficult to imagine a situation largely free of prejudice and discrimination in the "real world" of a community meeting or other non-selective, heterogenous, gathering.

A "culturally safe space" is framed by an understanding that while there is a shared and common culture within a collective, there may also be significant cultural differences among the members of the gathering, and these differences are valued and respected. The creation of a culturally safe space is relatively easy in a homogenous collective without significant differences among its members. It is particularly challenging in a heterogenous, multi-cultural collective where a balance must be found between supporting the common cultural elements while embracing differences at the same time. The emphasis on common or shared culture is particularly important from the perspective of healing collective trauma. It is critical, however, to be mindful that excessive emphasis of commonality risks extinguishing individuality and differences.

\section{Shared Experiences and Collective Healing}

There is a common assumption that the process of healing a collective trauma is necessarily "collective" in approach, and the experience should be one that is shared. ${ }^{36}$ The rationale for this widespread assumption is not clear, but there are three possibilities. The first is a belief that the woundedness of individuals within a collective is so great that its healing cannot be

\footnotetext{
35 Based on author's professional expert observations.

${ }^{36}$ Jack Saul, Collective Trauma, Collective Healing: Promoting Community Resilience in the Aftermath of Disaster (New York: Routledge, 2014); Ellen S. Zinner and Mary Beth Williams, When A Community Weeps: Case Studies in Group Survivorship (Philadelphia: Brunner/ Mazel, 1999).
} 
undertaken alone but needs the empathetic support of others within the collective who have had similar experiences, or preferably, shared some of their experiences, as illustrated by the effectiveness of survivor support groups. Often these groups are successful because they help individuals to overcome their tendency to avoid the painful exposure of their traumatic wound. In other words, the presence of collective forces is needed to draw the traumatized individuals from their state of withdrawal. Finally, the idea of a shared wound invites the notion of a common wound that requires common healing. This idea involves an imagined, singular collective wound that can only be healed through a process of the simultaneous healing of its affected members. ${ }^{37}$

The healing of a collective trauma can be compared to the process of mending a shattered picture; its pieces are like those of a jigsaw puzzle, needing to be brought together to form a whole image again. However, unlike the pieces of a jigsaw puzzle that are neatly cut and can be brought together perfectly, the pieces of a picture shattered or ripped apart by trauma are torn at their edges. The repair of these pieces with their jagged edges requires the presence of the adjoining pieces to define the gaps to be filled; the adjoining pieces may serve as a mold for each other to hold the filler binding them together. These adjoining pieces may be made up of supporting people who were not affected by that collective trauma. This process of repair may indeed serve as a metaphor for an aspect of the healing of historical collective trauma.

\section{Collective Memory, Contested History and Remembering}

There is a popular, but erroneous, belief that healing is marked by forgetting. ${ }^{38}$ However, the guilt of forgetting can lead one to cling to a distorted and fixed memory of what happened, where one becomes preoccupied by certain purported facts and loses sight of the whole picture. There is little room remaining for the emotionality of the events and for how one feels about it. From the perspective of healing, this is not remembering, but rather being stuck in a certain past. Furthermore, as I have outlined in the section on the psychology of trauma, the timelessness of trauma makes it difficult to distinguish the present from the past. Remembering in the context of healing, is different from the mere recollection of facts. It is a complex process of recalling what happened, being aware of how one felt about what happened then, and now, and appreciating the significance of what happened; a process that consists of aspects of working-through and making-sense, on which I will elaborate later.

The narrative of a collective traumatic event, especially an historically shared trauma, cannot accurately be recalled or recreated by one person. At best, it would be incomplete, and at worst, at risk of being biased. It is beyond the scope of this paper to discuss the complex issues around historiography and the numerous, relevant, critical points from the field of memory studies. ${ }^{39}$ If healing were to be considered from the psychoanalytic sense of "working through" the experience of a past event (see below), it follows that how that past is remembered is critical. In terms of individual psychology, the subjective past is what matters, notwithstanding the possibility that what we recall may be distorted by the trauma itself and the formative experiences that preceded it. However, when we come to collective psychology, the notions of memory and subjectivity are more complex.

There are personal differences between individuals in a collective as to what and how they remember a particular event and everyone's subjective experience will be unique. There are, however, some experiences in one person that approximate, but are not identical to, that of another in the collective. There might be sufficient similarity in the experiences of the two for them to be considered common or shared.

When we speak of shared grief over the loss of a particular person or ideal, we are not required to have the same experience of grief; indeed, it is impossible for each of us to have the

\footnotetext{
${ }^{37}$ Based on author's professional expert observations.

38 Ibid.

${ }^{39}$ Jeffrey K. Olick et al., "Introduction," in The Collective Memory Reader, ed. Jeffrey K. Olick et al. (New York: Oxford University Press, 2011).
} 
same subjective experience. The notion of shared grief involves two or more people having similar, but not identical, experiences of loss. Significantly, what is similar is not their personal experience or subjectivity but their shared interest in the object. For instance, collective mourning at a funeral is not about everyone being involved in a hypothetical (but impossible) merged, subjective experience of grief; it is about the commonality of what they have all lost.

When we speak of collective memory, we are referring both to the commonality of what we remember together as well as that which each person remembers individually. The notion of collective memory is indeed a vast and complex subject, much more than can be considered here. For the purposes of the healing of historical collective trauma, there must be room for both what we remember together and what we remember as individuals. The process of remembering together is challenging as it requires us to negotiate personal differences in recollections; a process that involves listening to each other to create a common narrative while allowing for unique personal memory. This is very much the essence of a collective workingthrough as I will discuss next. Remembering together is a difficult and demanding task. Often, we find it easier to delegate that task to an appointed or self-appointed historian, while arguing instead about contested issues in historiography.

\section{Working Through and Making Sense}

An influential psychological concept which is of the greatest relevance to healing is the idea that experiences need to be processed in order for them to be resolved to the extent that they cease to affect us. Freud described this process as "working through," a process of psychological work that involves remembering what has happened, reconnecting with the emotional response to that experience and making sense of what that experience meant to oneself. ${ }^{40}$ As I have outlined earlier in this paper, the mind acts to protect itself from trauma by encapsulating overwhelming experiences and detaching the associated emotional response to them, pushing both elements out of conscious awareness, leading to forgetting. The process of working through is the reverse; it begins with remembering and proceeds to reattach our emotional response to an experience, thereby re-creating the original situation for us to make sense of what it meant.

If collective healing were to consist of the processing of shared experiences, what would a collective working-through involve? Taking the lead from Freud, it would begin with remembering together and encompass a sharing of stories; each story by itself resembles an isolated broken piece from a shattered picture, waiting to be reassembled with other pieces to recreate the original whole image. There will be some similarities in the stories being shared. There are likely to be subtle differences even among what might appear to be similar in the first instance-differences that reflect individual subjectivity and personal background. If these moments of sharing stories consist only of the telling of factual elements of an event, unaccompanied by a sharing of associated emotions, they will not be of sufficient depth to possess the qualities of working through. The broken pieces may be assembled but considerable gaps will remain between them. A vital aspect of working through is the emotional response to what is remembered; the sharing of feelings about a common experience can be likened to the glue that holds the broken pieces together.

In recreating the shattered image, the collective now has the opportunity to look at the whole image, and make sense of it together, asking the questions: "What happened, and why did it happen?" This second question often takes them into a quest for meaning, into the realm of the spiritual and the transcendental. The search for answers to both these questions necessarily begins within a cultural context. As outlined earlier, culture provides the reference points for us to orientate ourselves, and the basic materials for each of us to create stories. When a group of us remember together and share our stories together, this process takes place within a cultural milieu that possesses commonalities and differences. The higher the proportion of shared cultural elements among members of a group, the closer the knit of their woven fabric of

\footnotetext{
${ }^{40}$ Sigmund Freud, "Remembering, Repeating and Working-Through," in Vol. 12, The Standard Edition of The Complete
} Psychological Works of Sigmund Freud, ed. James Strachey (London: Hogarth Press, [1914] 1955), 147-156. 
stories. On the other hand, the greater the proportion of different cultural strands, the richer the woven image. This metaphoric description demonstrates the way culture influences the stories we tell and the narratives we create, how we make sense of what happened in the past, and why it happened.

In practical terms, the process of memorialization creates the opportunity and space for a collective working-through. ${ }^{41}$ In his insightful observation of the process of building the United States Holocaust Memorial Museum, and his part in it, Gould highlighted the opportunity for people with shared trauma and loss to gather together to mourn while working constructively on the project. He noted, however, that the process was "a two-edged sword" with the inevitability of re-traumatization while also creating an opportunity to work through. ${ }^{42}$ $\mathrm{He}$ is, however, not the only person who holds the view that re-traumatization is a necessary part of the process of working through. ${ }^{43}$ While re-traumatization is usually carefully managed and supported in individual therapy, the challenge for those who promote a collective working through of trauma is the creation of a safe and supportive environment for hundreds and thousands who engage with public memorialization.

\section{Acknowledgement by Others}

There also seems to be a need for the reality of what happened to be acknowledged by Others in order for healing to take place. Recognition and validation by Others are particularly critical since many who experience traumatic events struggle to grasp the reality of what happened themselves; in many instances of genocides, the scale and depth of human cruelty is indeed beyond comprehension. Somehow, the acknowledgment of the reality of what happened by bystanders helps one to digest what is otherwise unthinkable.

The acknowledgement by those who carried out the atrocities brings added significance. There are a number of reasons for this. Firstly, in many instances, they are the only witnesses to what happened, and the only other who can know fully, what happened. Secondly, there is a need for at least one party to be responsible for what happened. In terms of individual psychology, when the person who carried out an assault refuses to accept responsibility for what happened, the burden of responsibility for what happened often falls on those assaulted. It is a well-recognized phenomenon that those who have suffered sexual assault often blame themselves for the incident. Thirdly, the issue of responsibility is keenly followed by the question of recompense for the hurt and injury caused, the absence of which is often accompanied by a painful resentment. 44

The tripartite acknowledgment of what happened-by those who suffered, those who caused it and those bystanders who recognized it for what it was (cf. victim, perpetrator, and witness)-usually emerges out of their distinct respective cultural contexts; each comes to understand what happened from their own cultural perspective. While the acceptance of these differences in perspectives is often necessary for healing to proceed, there is also a need for some shared understanding of what happened in order for the acknowledgment to be meaningful. For this reason, I think, the effort towards establishing a collective memory should, wherever possible, be a tripartite effort, encompassing the combined contributions of those who suffered, those who inflicted the injury and those who witnessed it.

\footnotetext{
${ }^{41}$ Laurence J. Gould, "Collective Working Through: The Role and Function of Memorialisation," Organisational and Social Dynamics 11, no. 1 (2011), 79-92.

42 Ibid., 8.

${ }^{43}$ Harold P. Blum, "Psychic Trauma and Traumatic Object Loss," Journal of the American Psychoanalytic Association 51 (2003).

44 The refusal by Japan to acknowledge "what happened" - in what is known in history as the Rape of Nanking during the Second Sino-Japan War-continues to foment a deep resentment towards them among many Chinese. See Rana Mitter, China's War with Japan: 1937-1945: The Struggle for Survival (London: Penguin Books, 2014); Iris Chang, The Rape of Nanking: The Forgotten Holocaust of World War II (New York: Basic Books, 2012).
} 


\section{Acknowledgement of Emotional Impact}

In practice, the purportedly factual acknowledgement of what happened, even when it is achieved through a tripartite, collaborative process, may not be sufficient. Traumatized individuals and collectives I have worked with over the years have needed acknowledgment by Others of how they felt about what happened. Such an acknowledgement also helps them to come to terms with how they have been affected emotionally. Historical discourses of collective traumatic events are often dispassionate-disassociated from the emotional response that might be expected to accompany such incidences; thus maintaining the emotional detachment described earlier.

The open exploration of how one party feels about what had happened to them is, however, fraught. It is beyond the scope of this paper to discuss the relative success and utility of Truth and Reconciliation Commissions, except to note that while they have created space for expressing much emotional pain of loss and suffering, and the airing of grievances, it is unclear if they have led to what is generally understood as healing. ${ }^{45}$ As this process is usually conducted in the presence of Others, the exposure of woundedness and vulnerability also risks further humiliation, compounding the original trauma. The possibility of sharing how one felt about their experience of certain atrocities, in the presence of those who have committed them, is perhaps far too fraught, and perhaps even unthinkable.

However, when an emotionally safe and supportive space can be created, and the pain of a traumatic experience can be shared by those who have suffered it, and if this is understood by those who inflicted the harm and witnessed by Others, a profound healing can take place. Cultures that encourage the sharing of emotional experiences and have in place social processes that regulate painful emotions such as shame and guilt are more likely to support such a collective acknowledgement of the emotional impact of a traumatic event.

\section{Making Sense of What Happened}

After the questions: (1) What happened? and (2) How does one feel about what happened?, what usually follows is: (3) Why did it happen? This question is an attempt to make sense of what had happened and one's emotional response to it.

One perspective on the need to make sense of trauma is the instinctual search for meaning, as suggested by Viktor Frankl. Another view is the need to orientate ourselves within a certain philosophy as part of our continuing efforts to find our place in this world. In ancient Greece, the cradle of modern Western civilization, everyday tragedies were contextualized within mythology. Vast proportions of the people in the world today still make sense of their life and suffering within the framework of their religious beliefs. ${ }^{46}$

When trauma occurs at the hands of another, or in the broader context of conflict, many in the modern world still return to basic notions of good and evil. Such simple, binary world views enable a person to locate themselves; at the very least, and most commonly, they lead them to see themselves as good. If we cannot locate ourselves within an adopted framework on an ordinary day, we will be left bewildered and adrift, lost and anxious when we are challenged by adversity; we will be completely overwhelmed by a major traumatic experience. 47

The Aboriginals in Australia try to make sense of their traumatic experiences within the context of their Culture and Law, which includes the narratives of Dreamtime stories and the order of the natural world according to their kinship systems. As outlined earlier, their culture has been distorted and destroyed by dispossession and the continuing pernicious effects of colonization. In my work with some communities, they were first encouraged to reclaim certain

\footnotetext{
45 Elizabeth Stanley, "Evaluating the Truth and Reconciliation Commission," The Journal of Modern African Studies 39, no. 3 (2001), 525-546, accessed April 26, 2021, https://doi.org/10.1017/S0022278X01003706; Brandon Hamber and Richard A. Wilson, "Symbolic Closure through Memory, Reparation and Revenge in Post-Conflict Societies," Journal of Human Rights 1, no. 1 (2002), 35-53, accessed April 26, 2021, https:/ / doi.org/10.1080/14754830110111553.

46 Viktor E. Frankl, Man's Search for Meaning (Boston: Beacon Press, 2006).

47 Based on author's professional expert observations.
} 
elements of their culture that were lost in order to reframe their trauma-the utility of their Dreamtime stories in helping them to understand their present-day predicament soon became apparent. One elder exclaimed, "we now understand that this terrible situation, this suffering, is not about our failures, our weaknesses (so say the colonizers) but what has happened to us, what we have lost, what has been done to us; we are right to feel sad, not shame." 48

\section{Cultural Trauma}

Relationship between Collective and Cultural Trauma

The traumatic event of the terrorist attack on the World Trade Centre on September 11 highlights the important difference between collective trauma and cultural trauma. All 2,977 individuals who died that day had the shared traumatic experience of being present at that time and place when that event unfolded, and it could be said that they shared a collective trauma. ${ }^{49}$ The same could be said of those who were in close proximity to that place and the hundreds of firefighters and rescue workers who attended. Many millions more, in the United States and worldwide, who watched the repeated screening of the airplanes crashing into the towers on television may have shared a collective vicarious trauma. For the Americans, however, it was arguably also a cultural trauma, as the Twin Towers of the World Trade Centre were a cultural icon for enterprise and national pride. It may also be construed as a cultural trauma for many in other commercial centers around the world, thousands of miles away, who looked upon the World Trade Centre as a symbol of the free market, trade, and capitalism, even though they may not have experienced any direct trauma either as individuals or as a collective.

Collective trauma and cultural trauma are overlapping concepts. As illustrated above, not all aspects of a collective trauma are cultural trauma and not all aspects of cultural trauma are experienced collectively. For example, a refugee or migrant may experience cultural trauma in their new host country; in this case, it might be a personal individual experience, or one shared with their family or others with a similar sense of cultural identity. This distinction between collective and cultural trauma is important when we consider potential approaches to healing.

In the context of this article-with its focus on the collective-cultural trauma is a subset of collective trauma, notwithstanding the exception of that experienced by individuals, as noted above.

\section{A Model of Culture}

Any conceptualization of cultural trauma is underpinned by the assumptions we make about the definition and nature of culture. While it is beyond the scope of this article to discuss the complex nature of culture and the confusion with regard to its definition, it is relevant that I present my understanding of culture. I offer below a brief outline of the relevant concepts for the purpose of our discussion here.

I take the meaning of the word culture from its Latin origin, cultura; its earliest use was found in the writings of the Roman statesman, historian, and philosopher, Cicero. $50 \mathrm{He}$ considered culture from the perspective of an agricultural metaphor: it is the soil that holds and nourishes us. When we speak of culture as that which influences our way of being in the world, we can begin to imagine how the constituents of soil may affect the character and growth of a plant and the fruit that it bears. The soil also holds the plant firmly in the ground and supports it to withstand the forces of wind and storm. In the language of psychology, culture holds and nurtures our sense of place in the world, our identity, and guides and regulates our relationships with each other. It supports our sense of confidence and security by providing a

\footnotetext{
${ }^{48}$ From notes of proceedings of a workshop on trauma for Aboriginal leaders in Central Australia in March 2015.

49 Hans-Jürgen Wirth, 9/11 as Collective Trauma: And other Essays on Psychoanalysis and Society (New York: Routledge, 2013).

${ }^{50}$ Marcus Tullius Cicero, Tusculan Disputations, trans. Charles Duke Yonge (New York: Harper \& Brothers, 1877).
} 
system of symbolic reference that help us make sense of our everyday experience and adverse events.

So much of what we often consider as culture, including customs, rituals, arts, language, and culinary delights are those aspects which are within our awareness. I refer to these elements of culture as cultural products. There are, however, aspects of culture that are not so apparent; I call them cultural substrates. These more basic forms of culture are transformed through cultural instruments (e.g. social institutions and their processes) into more elaborate forms and, if they are accepted by the vast majority of a collective, they become their cultural products.

Consider how Martin Luther King became an icon of American culture, or more specifically, a symbol of its civil rights movement. I proposed that his life, work, and death were a cultural substrate which, on its own, was not sufficient for him to become an icon or symbol, i.e. a cultural product. Rather, a series of cultural instruments turned the life, work, and death of a person into something that could be embraced by a collective. It might be argued that it was the mass shared experience of the life, work, and death of Martin Luther King that initiated the process of cultural transformation, the collective response to shared experience.

The national anthem of a country, the folk songs of an ethnic tradition and the Songlines of the Australian Aboriginals are all cultural products that have emerged from the collective responses of shared experiences. These sophisticated cultural products were developed and expressed through the established musical lexicon and symbolic language of each group and were themselves products that emerged from the shared experiences of their everyday life and historical events. Rituals and customs are formed through an evolution of the collective response to an experience of common situations and crises endured. The elaborate kinship system of many ancient cultures, including those of Australian Aboriginals, would have developed through a collective's experience of what was required to regulate relationships that ensured genetic diversity and peaceful communal life. This regulatory aspect of culture plays an important role in guiding our sense of place in the world.

When we say that we are held and nourished by our culture, this involves not only the customs, language, and arts of that culture, but also the poorly defined cultural substrates that have arisen from our shared collective responses and the cultural instruments that transform them into these recognizable cultural products.

\section{Two Types of Cultural trauma}

There are two models of cultural trauma. The first considers the traumatic experience in terms of defined events, and the second focuses on trauma as a continuous process. They reflect the two approaches in psychoanalytic thinking. Classical psychoanalysis focuses on how the mind responds to what it experiences, in particular to threats and psychically painful experiences, with a system of protective mechanisms, the most central of which, according to Freud is repression. ${ }^{51}$ It considers trauma in terms of specific external events that become embedded in the psyche; the mind reacts to them by repression and employs a host of defenses to keep the repressed from consciousness. The second approach, highlighted by work of Bion, focuses on the operation of the mind itself, how it thinks (e.g. the process of symbolization) and what influences its capacity to think. ${ }^{52}$ It considers trauma in terms of its overall impact on the development and functioning of the mind. approach:

Jeffrey Alexander and his colleagues have proposed a model according to the first

\footnotetext{
51 Sigmund Freud, "Repression," in Vol. 14, The Standard Edition of The Complete Psychological Works of Sigmund Freud, ed. James Strachey (London: Hogarth Press, [1915] 1955), 146-158.

52 Wilfred Ruprecht Bion, "The Psychoanalytic Study of Thinking," International Journal of Psycho-Analysis 43 (1962), 306310.
} 
Cultural trauma occurs when members of a collectivity feel they have been subjected to a horrendous event that leaves indelible marks upon their group consciousness, marking their memories forever and changing their future identity in fundamental and irrevocable ways. 53

This psychoanalytically informed sociological approach highlights the social processes by which a shared experience is collectively recognized as traumatic and how its impact is continually mediated through collective memory and representation. Ron Eyerman has applied this approach to his consideration of North Atlantic Slavery.54

In my opinion, it is insufficient to consider the cultural trauma of the slavery from the North Atlantic Slave Trade only as a defined event; the legacy of cultural dispossession and the forced adoption of the culture of those who had stripped enslaved people of their humanity have not received enough attention.

I have proposed a model called "complex cultural trauma;" it gives greater emphasis to the continuous experience of trauma and its impact on the function of the collective mind. ${ }^{55} \mathrm{I}$ have suggested that cultural trauma occurs when the apparatus or system through which a collective makes sense of its experience is corrupted, distorted, compromised or destroyed. The "thinking" apparatus or system of the collective mind, as we have earlier discussed, is its culture.

If we were to adopt the model of culture as outlined above, complex cultural trauma could begin with the corruption of cultural substrates; for example, by the overvaluing of some collective experiences over others or by censoring the response to particular shared experiences. The privileging of certain cultural processes while devaluing others will also distort the formation of cultural products. In some instances, such as colonization, slavery, and genocide, the whole cultural apparatus is compromised or destroyed. In many instances, cultural trauma involves a pervasive distortion or destruction of its substrates, instruments, and products as well as superimposed, defined events. Significantly, a destruction of a collective's thinking apparatus-its culture-will severely compromise its ability to make sense of definable adverse events.

\section{Healing Single, Defined-Event Cultural Trauma}

If cultural trauma is, as Jeffrey Alexander and colleagues have defined it, "a horrendous event that leaves indelible marks upon their group consciousness...," $" 56$ then the healing would involve a processing of that collective experience, with many of the elements described earlier in this paper.

The healing of cultural trauma involves collective remembering, which is a process of remembering together. It is a shared process of recalling what happened, the acknowledgement of how we all felt then and are feeling about it now, and an acknowledgment of its significance. How we remember together will be determined by the components of the culture we share-its substrates, processes, and products. Our common culture is laden with the assumptions we have consciously and unconsciously adopted. The colonized often assume their culture is inferior to that of the colonizer; they are deprived of certain components of their culture that could have given them a more authentic apprehension of their traumas. They would be creating

\footnotetext{
53 Jeffrey C. Alexander et al., Cultural Trauma and Collective Identity (Berkeley: University of California Press, 2004$), 1$.

54 Ron Eyerman, Cultural Trauma: Slavery and the Formation of African American Identity (Cambridge: Cambridge University Press, 2001).

55 The difference between Jeffrey Alexander's model of event-based cultural trauma and the cultural trauma I proposed may be compared to the distinction between content and the apparatus of a mind, or the software and operating system of a computer.

56 Alexander et al., Cultural Trauma and Collective Identity, 1.
} 
a narrative of their traumatic history without their own language, writing their story in someone else's language.

From the perspective of a cultural trauma, the Holocaust has, I think, entrenched forever, for many Jews, a deep sense of persecution, which is not only embedded in their identity but their whole way of life. Safety cannot be assumed and there is ever a vigilance for hatred. As I have highlighted earlier, when an individual or collective regresses under traumatic stress, their tendency towards binary thinking-that "if you are not for us, you are against us" -will influence their interaction with the rest of the world. These basic assumptions, being the substrates of their culture, will influence the creation of their cultural products, which include the writing of their history and the development of public policies.

The healing of the Holocaust trauma would require-more than the affirmation of collective memories-full and accurate representations of that traumatic experience and the process of working-through. It requires the most difficult task of re-examining, and sometimes undoing, basic assumptions relating to their fundamental sense of security and trust. ${ }^{57}$

\section{Healing Complex Cultural Trauma}

Complex cultural trauma often involves single-event trauma (which may be multiple) superimposed on a pervasive and continuous distortion and destruction of culture. The healing of those superimposing single-event traumas is limited by what has become of the underlying culture. It might be said that in many instances, progress in the healing of single-event trauma may not be possible without some healing of the underlying cultural apparatus.

One of the first steps in the healing of a collective's complex cultural trauma is its critical reexamination of relevant cultural substrates-their values and assumptions, and other more basic elements of the culture which are beyond everyday awareness.

The contributions of memory studies and critical cultural theories, especially from the post-colonial perspective, are therefore vital in ensuring that we have the most authentic collective thinking apparatus (our culture) possible to (re)frame what has happened, factually and emotionally, and make sense of it. This, I think, also applies to the healing of the Holocaust. It is, however, a most difficult task as attempts by the Jewish people to re-examine the basic assumptions of their own culture-under the cloud of "if you are not for us, you are against us," could quickly arouse accusations of betrayal. Sadly, if the cultural distortion caused by the Holocaust is not undone, the collective healing of this single, defined-event trauma will be limited, and the effects of this horrendous event will persist and pervade over many more generations to come.

For the Australian Aboriginals, colonized and dispossessed, and those affected by slavery, however, this will necessarily include a reclamation of their culture of origin. If that which has been lost, cannot be found, they will need to create new elements of culture, ones that are authentically theirs. It is beyond the scope of this paper to discuss further what this might involve, in particular, the complex process of decolonization.

\section{Conclusion}

Historical collective trauma is embedded in the shared consciousness of a collective, which this paper considers to be its culture. Its healing is a most complex and challenging task. At the core of it, is a collective process of working through painful, overwhelming experiences, a process that, at one level, involves remembering and making sense of defined events. This process is, however, dependent on the possession of a capable and authentic collective thinking apparatus, or culture. In many instances, the healing of single, defined traumatic events is limited by a pervasive, insidious and continuing distortion of, and damage to its underlying culture; a

\footnotetext{
${ }^{57}$ I wish to acknowledge the guidance of my esteemed Jewish colleagues, Dr. Paul Valent and Dr. George Halasz who are themselves survivors of the Holocaust. The views, expressed here, and the responsibility for any error, are mine alone.
} 
complex form of cultural trauma that needs to be addressed in order for the healing of historical collective trauma to be accomplished fully.

\section{Bibliography}

Akhtar, Salman. Mind, Culture, and Global Unrest: Psychoanalytic Reflections. London: Routledge, 2018.

Akhtar, Salman and Stuart W. Twemlow, eds. Textbook of Applied Psychoanalysis. Abingdon: Routledge, 2018.

Alexander, Jeffrey C., Ron Eyerman, Bernard Giesen, Neil J. Smelser, and Piotr Sztompka. Cultural Trauma and Collective Identity. Berkeley: University of California Press, 2004.

Alexander, Jeffrey C., Ronald N. Jacobs, and Philip Smith, eds. The Oxford Handbook of Cultural Sociology. New York: Oxford University Press, 2012.

Andermahr, Sonya. "Introduction." In "Decolonizing Trauma Studies: Trauma and Postcolonialism." Edited by Sonya Andermahr. Special issue, Humanities 4, no. 4 (2015), 500-505.

Auestad, Lene. Nationalism and the Body Politic: Psychoanalysis and the Rise of Ethnocentrism and Xenophobia. London: Karnac, 2014.

Bion, Wilfred Ruprecht. "The Psychoanalytic Study of Thinking." International Journal of PsychoAnalysis 43 (1962), 306-310.

Blum, Harold P. "Psychic Trauma and Traumatic Object Loss." Journal of the American Psychoanalytic Association 51 (2003), 415-431.

Brunning, Halina and Mario Perini, eds. Psychoanalytic Perspectives on the Turbulent World. London: Karnac, 2010.

Bush, George W. "State of the Union Address: Text of George Bush's Speech." The Guardian, September 21, 2001. Accessed April 27, 2020. https://www.theguardian.com/world/ 2001/sep/21/september11.usa13.

Chang, Iris. The Rape of Nanking: The Forgotten Holocaust of World War II. New York: Basic Books, 2012.

Cicero, Marcus Tullius. Tusculan Disputations. Translated by Charles Duke Yonge. New York: Harper \& Brothers, 1877.

Craps, Stef, Bryan Cheyette, Alan Gibbs, Sonya Andermahr, and Larissa Allwork. “Decolonizing Trauma Studies Round-Table Discussion.” In “Decolonizing Trauma Studies: Trauma and Postcolonialism." Edited by Sonya Andermahr. Special issue, Humanities 4, no. 4 (2015), 905-923.

Danieli, Yael, ed. International Handbook of Multigenerational Legacies of Trauma. New York: Plenum Press, 1998.

Donald, James, ed. Psychoanalysis \& Cultural Theory. London: MacMillan Education, 1991.

Eyerman, Ron. Cultural Trauma: Slavery and the Formation of African American Identity. Cambridge: Cambridge University Press, 2001.

Frankl, Viktor E. Man's Search for Meaning. Boston: Beacon Press, 2006.

Freud, Sigmund. "Group Psychology and the Analysis of the Ego." In Vol. 18 of The Standard Edition of The Complete Psychological Works of Sigmund Freud, edited by James Strachey, 67-134. London: Hogarth Press, [1921] 1955.

------. "Remembering, Repeating and Working-Through." In Vol. 12 of The Standard Edition of The Complete Psychological Works of Sigmund Freud, edited by James Strachey, 147-156. London: Hogarth Press, [1914] 1955.

------. "Repression." In Vol. 14 of The Standard Edition of The Complete Psychological Works of Sigmund Freud, edited by James Strachey, 146-158. London: Hogarth Press, [1915] 1955.

Gould, Laurence J. "Collective Working Through: The Role and Function of Memorialisation." Organisational and Social Dynamics 11, no. 1 (2011), 79-92.

Hamber, Brandon and Richard A. Wilson. "Symbolic Closure through Memory, Reparation and Revenge in Post-Conflict Societies." Journal of Human Rights 1, no. 1 (2002), 35-53. Accessed April 26, 2021. https:/ / doi.org/10.1080/14754830110111553. 
Hamilton, James W. A Psychoanalytic Approach to Visual Artists. London: Karnac, 2012.

Hoggett, Paul. Politics, Identity and Emotions. Boulder: Paradigm Publishers, 2009.

Hopper, Earl. "Encapsulation as a Defence against the Fear of Annihilation." The International Journal of Psycho-Analysis 72, no. 4 (1991), 607-624.

Jaques, Elliott. "Social Systems as a Defence against Persecutory and Depressive Anxiety." In New Directions in Psychoanalysis, edited by Melanie Klein, Paula Hermann, and R. E. Money-Kyrle, 478-498. London: Tavistock Publications, 1955.

Jones, Adam. Genocide: A Comprehensive Introduction. Oxford: Routledge, 2016.

Kellermann, Natan P. F. Holocaust Trauma: Psychological Effects and Treatment. New York: iUniverse Inc., 2009.

Koh, Eugen. "Cultural Work in Addressing Violence and Conflict in Traumatized Communities." New England Journal of Public Policy 31, No. 1 (2019), 1-14. Accessed April 24, 2021. https://scholarworks.umb.edu/nejpp/vol31/iss1/3/.

Koh, Eugen and George Halasz. "Back of House/Under the House: Some Psychoanalytic Aspects of the Acquisition and Exhibition of Art by Survivors of the Holocaust." International Journal of Applied Psychoanalytic Studies 8, no. 1 (2011), 74-88. Accessed April 24, 2021. https:// doi.org/10.1002/aps.276.

Koh, Eugen and Tadashi Takeshima. "The Long-Term Effects of Japan's Traumatic Experience in the Second World War and its Implications for Peace in Northeast Asia." New England Journal of Public Policy 32, no. 2 (2020), 1-13. Accessed December 21, 2020. https:// scholarworks.umb.edu/nejpp/vol32/iss2/5/.

Laplanche, Jean and Jean-Bertrand Pontalis. The Language of Psycho-Analysis. London: Karnac Books, 1973.

Le Bon, Gustave. Psychologie des foules. Paris: Félix Alcan, 1895.

MacCabe, Colin, Holly Yanacek, and The Keywords Project, eds. Keywords for Today: A 21st Century Vocabulary. New York: Oxford University Press, 2018.

McDougall, William. The Group Mind. London: Cambridge University Press, 1920.

Menzies, Isabel E. P. "A Case Study in the Functioning of Social Systems as a Defence against Anxiety: A Report on a Study of the Nursing Service of a General Hospital." Human Relations 13, no. 2 (1960), 95-121.

Mitter, Rana. China's War with Japan: 1937-1945: The Struggle for Survival. London: Penguin Books, 2014.

Moses, A. Dirk., ed. Genocide and Settler Society: Frontier Violence and Stolen Indigenous Children in Australian History. New York: Berghahn Books, 2004.

Olick, Jeffrey K., Vered Vinistzky-Seroussi, and Daniel Levy. "Introduction.” In The Collective Memory Reader, edited by Jeffrey K. Olick, Vered Vinistzky-Seroussi and Daniel Levy, 362. New York: Oxford University Press, 2011.

Pikoulis, Emmanouil A., John C. B. Petropoulos, Christos Tsigris, Nikolaos Pikoulis, Ari K. Leppäniemi, Emmanouil Pavlakis, Evgenia Gavrielatou, David Burris, Elias Bastounis, and Norman M. Rich. "Trauma Management in Ancient Greece: Value of Surgical Principles through the Years." World Journal of Surgery 28, no. 4 (2004), 425-430.

Prell, Christina. Social Network Analysis: History, Theory \& Methodology. London: Sage Publications, 2012.

Samuels, Andrew. The Political Psyche. London: Routledge, 1993.

Saul, Jack. Collective Trauma, Collective Healing: Promoting Community Resilience in the Aftermath of Disaster. New York: Routledge, 2014.

Spitz, Ellen Handler. Art and Psyche. New Haven: Yale University Press, 1985.

Stanley, Elizabeth. "Evaluating the Truth and Reconciliation Commission." The Journal of Modern African Studies 39, no. 3 (2001), 525-546. Accessed April 26, 2021. https://doi.org/ $10.1017 /$ S0022278X01003706.

Stapley, Lionel F. The Personality of the Organization: A Psycho-Dynamic Explanation of Culture and Change. London: Free Association Books, 1996. 
van der Kolk, Bessel. The Body Keeps the Score: Brain, Mind, and Body in the Healing of Trauma. New York: Viking, 2014.

Volkan, Vamik D. Psychoanalysis, International Relations and Diplomacy: A Sourcebook on LargeGroup Psychology. London: Karnac, 2014.

Wirth, Hans-Jürgen. 9/11 as Collective Trauma: And other Essays on Psychoanalysis and Society. New York: Routledge, 2013.

Zinner, Ellen S. and Mary Beth Williams. When A Community Weeps: Case Studies In Group Survivorship. Philadelphia: Brunner/Mazel, 1999. 